\title{
Status and New Data of the Geochemical Determination of the pp-Neutrino Flux by LOREX
}

\author{
M. K. Pavićević, ${ }^{1}$ F. Bosch, ${ }^{2}$ G. Amthauer, ${ }^{1}$ I. Aničin, ${ }^{3}$ \\ B. Boev, ${ }^{4}$ W. Brüchle, ${ }^{5}$ V. Cvetković, ${ }^{6}$ Z. Djurčić, ${ }^{7}$ W. F. Henning, ${ }^{8}$ \\ R. Jelenković, ${ }^{6}$ V. Pejović, ${ }^{3}$ and A. Weiss ${ }^{9}$ \\ ${ }^{1}$ Division of Material Sciences and Physics, Department of Mineralogy, University of Salzburg, \\ Hellbrunner Street 34, 5020 Salzburg, Austria \\ ${ }^{2}$ GSI Helmholtzzentrum für Schwerionenforschung, Planck Straße 1, 64291 Darmstadt, Germany \\ ${ }^{3}$ Institute of Physics, University of Belgrade, Pregrevica 118, 11000 Belgrade, Serbia \\ ${ }^{4}$ Faculty of Mining and Geology, Goce Delčev University of Štip, Goce Delčev 89, 92000 Štip, Macedonia \\ ${ }^{5}$ GSI Helmholtzzentrum für Schwerionenforschung, Planck Straße. 1, 64291 Darmstadt, Germany \\ ${ }^{6}$ Faculty of Mining and Geology, University of Belgrade, Đusina 7/II, 11000 Belgrade, Serbia \\ ${ }^{7}$ Physics Division, Argonne National Laboratory (ANL), 9700 South Cass Avenue, \\ Argonne, IL 60439, USA \\ ${ }^{8}$ Physics Department E12, Technical University of Munich, James-Franck Street, \\ 85748 Garching, Germany \\ ${ }^{9}$ Max-Planck Institute for Astrophysics, Karl-Schwarzschild Street 1, 85741 Garching, Germany
}

Correspondence should be addressed to M. K. Pavićević, miodragk.pavicevic@gmail.com

Received 21 August 2012; Revised 19 October 2012; Accepted 2 November 2012

Academic Editor: Bogdan Mitrica

Copyright (c) 2012 M. K. Pavićević et al. This is an open access article distributed under the Creative Commons Attribution License, which permits unrestricted use, distribution, and reproduction in any medium, provided the original work is properly cited.

LOREX (LORandite EXperiment) addresses the determination of the solar (pp) neutrino flux during the last four million years by exploiting the reaction ${ }^{205} \mathrm{Tl}+v_{\mathrm{e}} \rightarrow{ }^{205} \mathrm{~Pb}+\mathrm{e}^{-}$with an incomparably low-energy threshold of $50 \mathrm{keV}$ for the capture of solar neutrinos. The ratio of ${ }^{205} \mathrm{~Pb} /{ }^{205} \mathrm{Tl}$ atoms in the Tl-bearing mineral lorandite provides, if corrected for the cosmic-ray induced background, the product of the flux of solar neutrinos and their capture probability by ${ }^{205} \mathrm{Tl}$, averaged over the age of lorandite. To get the mean solar neutrino flux itself, four problems have to be addressed: (1) the geological age of lorandite, (2) the amount of background cosmicray-induced ${ }^{205} \mathrm{~Pb}$ atoms which strongly depends on the erosion rate of the lorandite-bearing rocks, (3) the capture probability of solar neutrinos by ${ }^{205} \mathrm{Tl}$ and (4) the extraction of lorandite and the appropriate technique to "count" the small number of ${ }^{205} \mathrm{~Pb}$ atoms in relation to the number of ${ }^{205} \mathrm{Tl}$ atoms. This paper summarizes the status of items 1 (age) and 3 (neutrino capture probability) and presents in detail the progress achieved most recently concerning the items 2 (background/erosion) and 4 ("counting" of ${ }^{205} \mathrm{~Pb}$ atoms in lorandite). 


\section{Introduction}

The determination of the long-time average of the solar neutrino flux $\Phi_{v}$ with the thalliumbearing mineral lorandite, $\mathrm{TlAsS}_{2}$, from the mine of Allchar, Macedonia, is based on the neutrino capture reaction proposed by Freedman et al., 1976 [1]:

$$
{ }^{205} \mathrm{Tl}+v_{\mathrm{e}} \longrightarrow{ }^{205} \mathrm{~Pb}+\mathrm{e}^{-}
$$

The average flux $\left\langle\Phi_{v}\right\rangle$ over the exposure time $a$ (age of lorandite since its mineralization) follows from the common activation equation:

$$
\Phi_{v}=N^{-1}(T-B)(\sigma \varepsilon)^{-1} \lambda[1-\exp (-\lambda a)]^{-1},
$$

where $N$ is the total number of ${ }^{205} \mathrm{Tl}$ atoms, $T$ the total number of ${ }^{205} \mathrm{~Pb}$ atoms, $B$ the number of ${ }^{205} \mathrm{~Pb}$ atoms induced by background reactions (mainly $\left.{ }^{205} \mathrm{Tl}(\mu p, n){ }^{205} \mathrm{~Pb}\right), \sigma$ the solar neutrino capture cross-section of ${ }^{205} \mathrm{Tl}, \varepsilon$ the overall detection efficiency, $\lambda$ the decay constant of ${ }^{205} \mathrm{~Pb}$ and $a$ the geological age of lorandite (i.e., the age of mineralization).

The neutrino capture reaction:

$$
{ }^{205 \mathrm{~s}} \mathrm{Tl}+v_{\mathrm{e}}\left(E_{v \mathrm{e}} \geq 50 \mathrm{keV}\right) \longrightarrow{ }^{205} \mathrm{~Pb}^{*}+\mathrm{e}
$$

exploits the by far lowest threshold of $E_{v e} \geq 50 \mathrm{keV}$ for solar neutrinos.

The last step and the central problem of LOREX is the quantitative determination of ${ }^{205} \mathrm{~Pb}$ atoms in lorandite. This renders finally the mean solar neutrino flux, that is, the mean luminosity of the sun during the last 4.31 million years, which is the geological age $a$ of lorandite from Allchar, as given by Neubauer et al. [2]. Before entering the final phase of the experiment, four problems must be reliably addressed; however,

(1) the age $a$ of lorandite has to be known precisely: age of lorandite,

(2) the background of ${ }^{205} \mathrm{~Pb}$ atoms produced by cosmic radiation (mainly $(\mu p, n)$ reactions) and by natural radioactivity must be determined quantitatively. In this context the knowledge of the erosion rate of the overburden rocks during the existence of lorandite is of utmost importance: background and erosion,

(3) the ratio ${ }^{205} \mathrm{~Pb} /{ }^{205} \mathrm{Tl}$ provides only the product of solar neutrino flux and neutrino capture probability into different nuclear states of ${ }^{205} \mathrm{~Pb}$. However, the capture of neutrinos should populate predominantly the first excited state at $E^{*}=2.3 \mathrm{keV}$. Hence, to get the neutrino flux itself, one has to determine the capture probability into this low-lying state of ${ }^{205} \mathrm{~Pb}$ : neutrino capture probability into the $2.3 \mathrm{keV}$ state of ${ }^{205} \mathrm{~Pb}$,

(4) how can the expected ultra-low abundance of ${ }^{205} \mathrm{~Pb}$ be reliably measured: detection of ${ }^{205} \mathrm{~Pb}$. 


\section{Main Directions of Present and Future Investigations}

\subsection{Age of Lorandite}

The age of the Tl mineralization is an essential parameter of the experiment, as it equals the integration time of mineral lorandite as the geochemical pp-solar neutrino detector. As it turned out, another important prerequisite for the realization of LOREX is that the ore deposit has to provide for more than two lorandite-rich ore bodies, located at significantly different depths.

Geological research demonstrated that lorandite in sufficient quantities occurs in the Allchar Sb-As-Tl-Au deposit located in FYR Macedonia at the north-western margins of the Kožuf Mountains, close to the border between FYR Macedonia and Greece. The mine contains the world's largest known concentrations of thallium-bearing minerals and, in particular, the mineral lorandite. The polychronous and polygenetic Sb-As-Tl-Au Allchar deposit was formed by complex physicochemical processes occurring in a heterogeneous geological environment. The deposit originated through polyphase interactions of hydrothermal fluids and the surrounding magmatic, sedimentary, and metamorphic rocks. The genesis of ore mineralization is genetically related to the products of Pliocene magmatic activity. The spatial location of the mineralization was controlled by magmatic, structural, and lithological factors as suggested by Janković and Jelenković [4]. The Allchar deposit comprises several ore bodies of various shapes, textural and structural characteristics, and associations of elements.

Thallium mineralization has been proved in two locations, that is, two ore bodies: Crven Dol and Centralni Deo ore bodies, situated in the northern and central part of the Allchar deposit, respectively, (Figure 1).

Troesch and Frantz determined the geological age of Tl mineralization in Crven Dol (Figure 1(a)) as $4.22 \pm 0.07 \mathrm{Ma}$, using sanidine from adit number 21 [5]. This determination was obtained by isochrone ${ }^{40} \mathrm{Ar} /{ }^{39} \mathrm{Ar}$ five-degree measurement of argon content with the derivation $2 \sigma$ of the first phase and $1 \sigma$ of other four phases.

During the final stages of volcanic activity in the Allchar area occurred hydrothermal alteration of the wall rocks, and this can be considered as the period of initial deposition of ore minerals in this area. The age of K-feldspars (alkali feldspar has a general formula: $(\mathrm{K}, \mathrm{Na}) \mathrm{AlSi}_{3} \mathrm{O}_{8}$, but varies in crystal structure depending on the temperature it formed at; the formula actually is a blend ranging from pure sodium (albite) to pure potassium end-member orthoclase, microcline, or sanidine) in an altered zone at the Rudina locality is $4.31 \pm 0.02 \mathrm{Ma}$ according to Neubauer et al. [2], which documents the beginning of intensive alteration and deposition of thallium mineralization. The close spatial association of mineralization and hydrothermally altered rocks is found by a drill-core B-2 (Figure 1(b)) of the Rio Tinto company in 1999 at the Rudina locality, which is geologically connected with the ore body Centralni Deo. These drill cores revealed the presence of As-, Sb-, and S-mineralization and strongly altered rocks at depth intervals $30-60 \mathrm{~m}$ and $160-280 \mathrm{~m}$, respectively, from Rio Tinto Co. [3].

\subsection{Background Reactions and Cosmic Ray Contribution}

In the case of LOREX more than 30 processes have been identified and analyzed which potentially contribute to the "background" of ${ }^{205} \mathrm{~Pb}$. After careful evaluation only four processes turned out to potentially have nonnegligible contributions:

(1) the ${ }^{205} \mathrm{Tl}(\mu p, n)^{205} \mathrm{~Pb}$ reaction: contribution of fast muons, 


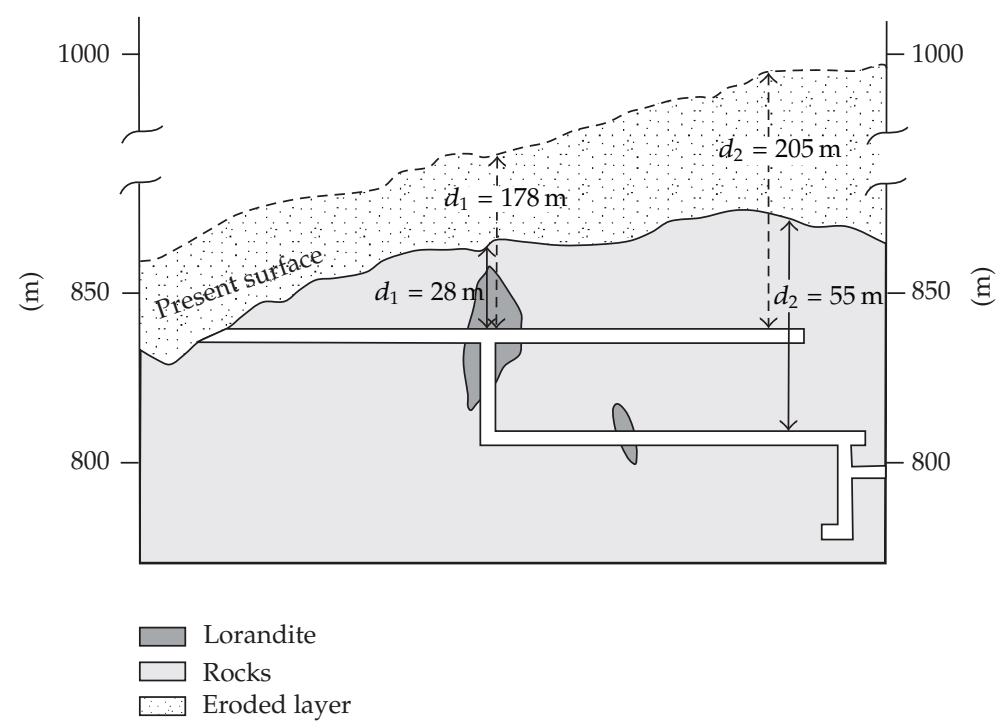

(a) Crven Dol, Adit P-21

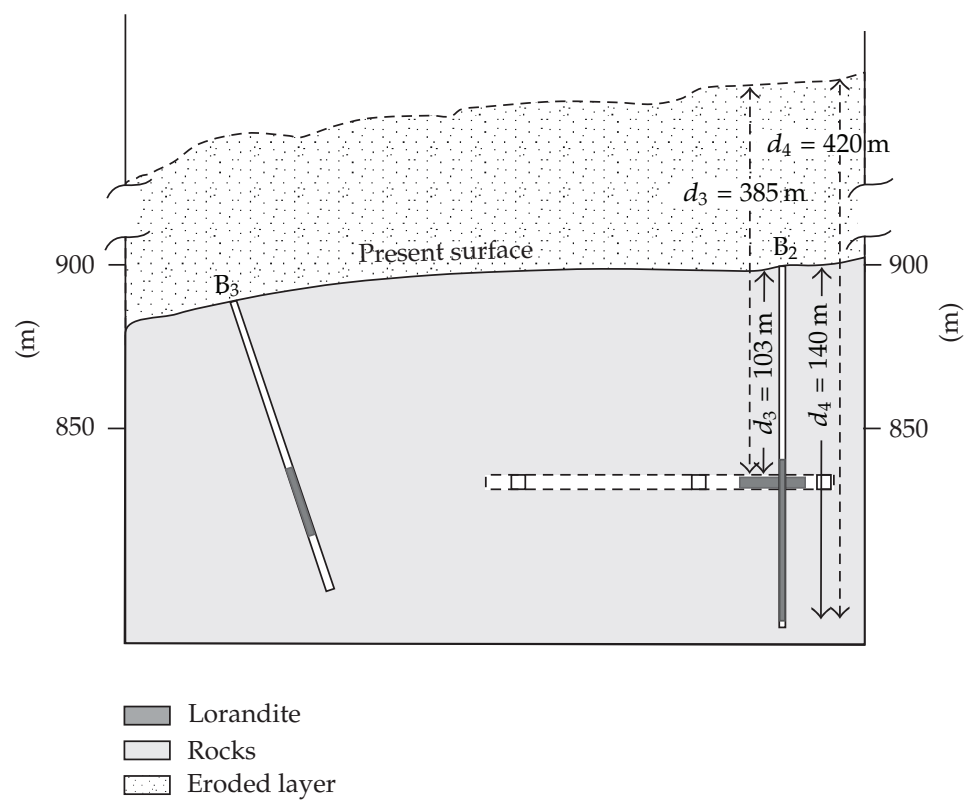

(b) Centralni Deo, Adit 823

Figure 1: Geological cross-section of the ore body Crven Dol (a) and Centralni Deo (b) of the Allchar ore deposit together with the presumably eroded layer.

(2) the ${ }^{205} \mathrm{Tl}(\mu p, n)^{205} \mathrm{~Pb}$ reaction: contribution of stopped muons,

(3) the ${ }^{204} \mathrm{~Pb}(n, \gamma)^{205} \mathrm{~Pb}$ and ${ }^{206} \mathrm{~Pb}(n, 2 n)^{205} \mathrm{~Pb}$ reactions,

(4) ${ }^{205} \mathrm{~Pb}$ mobilized from the environment of lorandite.

Figure 2 shows present estimates of different contributions to the production of ${ }^{205} \mathrm{~Pb}$ in lorandite on the basis of the erosion rate $70 \mathrm{~m} / \mathrm{Ma}$ and $130 \mathrm{~m} / \mathrm{Ma}$, traces of $\mathrm{U}$ and $\mathrm{Th}$ 
Table 1: Cosmic-ray contributed $N_{\mu^{-}}$and total number $N_{t}$ of ${ }^{205} \mathrm{~Pb}$ atoms per $10 \mathrm{~kg}$ of lorandite from different depths, known to contain significant quantities of lorandite.

\begin{tabular}{lcccccc}
\hline $\begin{array}{l}\text { Depth of } \\
\text { location } \\
(\mathrm{m})\end{array}$ & $\begin{array}{c}\text { Erosion } \\
\text { rate } \\
(\mathrm{m} / \mathrm{Ma})\end{array}$ & $\begin{array}{c}\text { Paleo-depth } \\
d_{p} \text { of } \\
\text { location } \\
(\mathrm{mwe})\end{array}$ & $\begin{array}{c}N\left(\mathrm{~Pb}^{205}\right)_{\text {fast muons }} \\
\times 10^{4} \\
\text { (at. } 10 \mathrm{~kg}^{-1} \\
\text { lorandite })\end{array}$ & $\begin{array}{c}N\left(\mathrm{~Pb}^{205}\right)_{\text {total }} \\
\times 10^{4} \\
\left(\text { at. } 10 \mathrm{~kg}^{-1}\right. \\
\text { lorandite })\end{array}$ & $\begin{array}{c}N\left(\mathrm{~Pb}^{205}\right)_{v} \\
\%\end{array}$ & $\begin{array}{c}N\left(\mathrm{~Pb}^{205}\right)_{\text {fast muons }} \\
\%\end{array}$ \\
\hline$d_{1}=28$ & 70 & 455 & 93.8 & 115.8 & 19.0 & 81.0 \\
$d_{2}=55$ & 70 & 525 & 56.9 & 78.9 & 27.9 & 72.1 \\
$d_{3}=103$ & 130 & 980 & 18.6 & 40.6 & 54.2 & 45.8 \\
$d_{4 \max }=140^{*}$ & 130 & 1070 & 13.0 & 35.0 & 62.8 & 37.2 \\
\hline
\end{tabular}

"Drillings of Rio Tinto Exploration Ltd. [3] (see Figure 1(b)).

in lorandite and surrounding rocks by Pavićević [6], and the method by Heisinger and coworkers [7] as a function of the paleodepth $d_{p}$ of the deposit.

To determine the erosion rate in Allchar we applied terrestrial in situ cosmogenic nuclides including both radioactive $\left({ }^{10} \mathrm{Be}\right.$ and $\left.{ }^{26} \mathrm{Al}\right)$ and stable $\left({ }^{3} \mathrm{He}\right.$ and $\left.{ }^{21} \mathrm{Ne}\right)$ nuclides in different minerals and compared the obtained data with the results of geomorphologic analysis. ${ }^{26} \mathrm{Al}$ concentrations of 16 samples have $1 \sigma$ uncertainties of $26-58 \%$ and yield maximum erosion rates from $\sim 70 \mathrm{~m} / \mathrm{Ma}$ to $\sim 600 \mathrm{~m} / \mathrm{Ma}$ at different locations. The noble gas analyses included measurements of ${ }^{3} \mathrm{He}$ in one diopside sample and ${ }^{21} \mathrm{Ne}$ in quartz from five different locations and in one sanidine sample, revealing erosion rates between $\sim 20 \mathrm{~m} / \mathrm{Ma}$ and $\sim 70 \mathrm{~m} / \mathrm{Ma}$, with asymmetric $1 \sigma$ uncertainties between 10 and $200 \%$. The ${ }^{10} \mathrm{Be}$ measurements revealed unrealistically high values and had to be omitted from interpretation. Both the combined ${ }^{21} \mathrm{Ne}^{26} \mathrm{Al}$ data and the geological information indicate that a simple steady-state erosion history is not applicable to the Allchar area. Rather, long periods of burial $(\sim 500 \mathrm{ka}-3 \mathrm{Ma})$ by volcaniclastic material and, possibly, glacier ice have interrupted the times of exposure and erosion. Nevertheless, it is remarkable that $85 \%$ of all erosion rate values determined from different cosmogenic nuclides $\left({ }^{3} \mathrm{He},{ }^{21} \mathrm{Ne},{ }^{26} \mathrm{Al}\right)$ in various monitor minerals at various locations, as well as the results of geomorphologic analysis, yield consistent results in the range from $\sim 20$ to $\sim 90 \mathrm{~m} / \mathrm{Ma}$. We argue that the ${ }^{26} \mathrm{Al}$ concentrations most likely reflect the erosion rate during the last, postburial period $(\sim 100 \mathrm{ka})$. For the two most important Allchar locations with lorandite ore bodies Crven Dol and Centralni Deo we propose the erosion rates of $\sim 70 \mathrm{~m} / \mathrm{Ma}$ and $\sim 130 \mathrm{~m} / \mathrm{Ma}$, respectively, according to Pavićević et al. [8]. The paleodepths for the four confirmed ore-bodies with significant quantity of lorandite are found from their present-day depths and the estimated thickness of eroded layers at corresponding locations (Figure 1 and Table 1).

Table 1 also lists the final estimates of concentrations of ${ }^{205} \mathrm{~Pb}$ (atoms per $10 \mathrm{~kg}$ lorandite) at different depths; the concentration due to the cosmic-ray fast muons, the concentration due to pp-neutrino captures, and the total concentration. For the shallowest location $d_{1}$ the neutrino contribution amounts to $\sim 20 \%$, while for the deepest one $d_{4}$ it amounts to $\sim 63 \%$.

As seen in Figure 2, concentrations of ${ }^{205} \mathrm{~Pb}$ in samples from different depths reflectdue to the muon contribution which is depth dependent-both the present-day depth of the sample as well as the erosion history of the overburden layers. Curves that correspond to different average erosion rates form a family of exponentials (Aničin et al. [10]) and experimental determination of ${ }^{205} \mathrm{~Pb}$ concentrations in samples from a number of different depths allow for the simultaneous determination of both the muon contribution and 


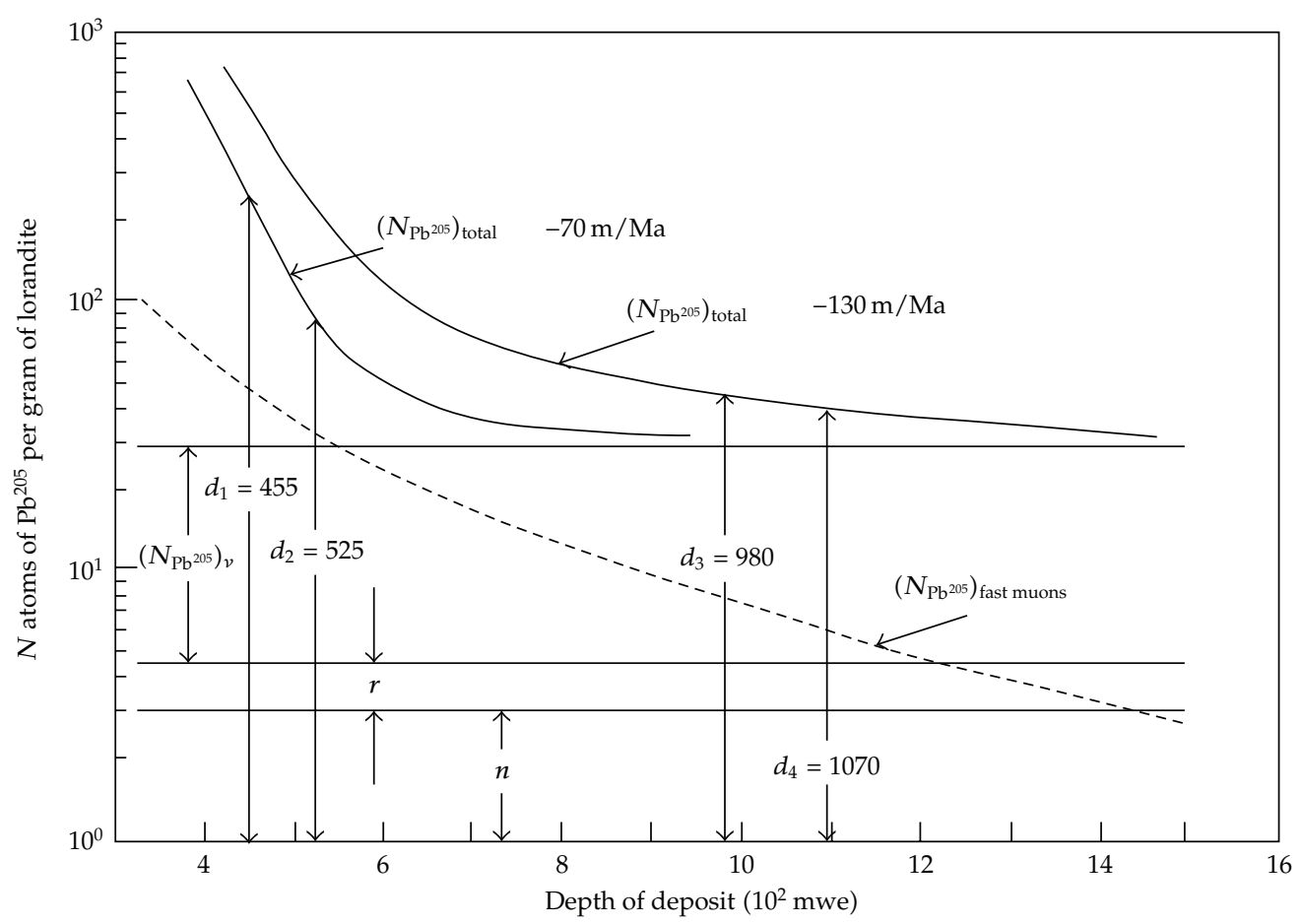

Figure 2: Estimate of the present amount of ${ }^{205} \mathrm{~Pb}$ in lorandite due to solar neutrinos and to background reactions in the last $4.31 \cdot 10^{6}$ years as a function of the paleodepth $d_{p}$ of lorandite. The values are calculated by Pejović by adopting the value of $0.55 \mu \mathrm{b}$ for the neutrino capture cross-section for ${ }^{205} \mathrm{Tl}$ from Hartman et al. [9], the contents of $U$ and Th in lorandite and surrounding rocks are from Pavićević [6] and the method of Heisinger et al. [7]. $n$ : contributions due to lead mobilized from the rock walls. $r$ : contributions from natural radioactivity. $\mathrm{N}\left(\mathrm{Pb}^{205}\right)_{\text {fast muons }}$ : contribution due to reactions induced by fast cosmic muons. $\mathrm{N}\left(\mathrm{Pb}^{205}\right)_{v}$ : number of $\mathrm{Pb}^{205}$ due to solar neutrino capture, for a capture rate of $146 \mathrm{SNU}$ $\left(1 \mathrm{SNU}=10^{-36} \mathrm{captures} /(\right.$ target atoms $\left.\cdot \mathrm{sec})\right)$, obtained after correcting the original $260 \mathrm{SNU}$ value for neutrino flavour-oscillations. $\mathrm{N}\left(\mathrm{Pb}^{205}\right)_{\text {total }}$ : the sum of the neutrino contribution and of all background contributions.

the erosion history of the deposit. The contribution due to the ${ }^{205} \mathrm{~Pb}$ mobilized from the surrounding rock at the time of lorandite mineralization, marked by " $n$ ", and that due to natural radioactivity in lorandite and in the surrounding rocks, marked by " $r$ ", contribute together by less than $4 \%$ to the total concentration ( $\mathrm{U}$ and Th concentrations are low: marble, dolomite, and quartz latite have contents of $U$ in the range of $0.054-0.45 \mathrm{ppm}$ and Th of $0.061-0.66 \mathrm{ppm}$, while the mean concentrations in lorandite amount to $0.12 \mathrm{ppm}$ for $\mathrm{U}$ and $0.022 \mathrm{ppm}$ for Th, respectively, as given by Pavićević [6].

Estimate of contribution of " $n$," that is, mobilised ${ }^{205} \mathrm{~Pb}$ from surrounding rocks at the time of the formation of the Tl-mineralization (age of lorandite) and the natural radioactivity contribution " $r$," as consequence trace concentrations of $U$ and Th amount to less than $4 \%$ (see Figure 2). The low contribution of " $n$ " is consequence of the very low concentration of $U$ and Th in rocks: marble, dolomite, and Qz-rhyolite, which have the content of $\mathrm{U}=0.054-0.45 \mathrm{ppm}$ and Th $0.061-0.66 \mathrm{ppm}$ (Pavićević [6]). The contribution of natural radioactivity " $r$ " that is predominantly caused by $U$ and Th in lorandite is low due to low concentrations of these elements in lorandite: $U=0.12 \mathrm{ppm}$ and Th $0.022 \mathrm{ppm}$ 
(Pavićević [6]). All background components not specific to lorandite (not originating from thallium) were estimated to amounts of between 3 and 15SNU (Neumaier et al. [11]) and can experimentally be determined by measuring the ${ }^{205} \mathrm{~Pb}$ contents in monitoring minerals (realgar $\mathrm{As}_{2} \mathrm{~S}_{2}$ and orpiment $\mathrm{As}_{2} \mathrm{~S}_{3}$ ).

From the data for $\mathrm{N}\left(\mathrm{Pb}^{205}\right)_{v}$ and $\mathrm{N}\left(\mathrm{Pb}^{205}\right)_{\text {fast muons }}$ shown in Table 1 we estimated by a Monte Carlo simulation the mean neutrino flux $\left\langle\Phi_{v}\right\rangle$ (1.2) during the geological age $a$ of lorandite as

$$
\left\langle\Phi_{v}\right\rangle=(3.41 \pm .44) 10^{10} \mathrm{~m}^{-2} \mathrm{sec}^{-1}
$$

by using the following parameters (see (1.2)):

$$
N=1.25 \cdot 10^{25}\left(2.5 \cdot 10^{23}\right) \text { atoms of }{ }^{205} \mathrm{Tl}
$$

This number corresponds to $10 \mathrm{~kg}$ of lorandite, collected at a sufficiently deep location, for the background $B$ to be acceptable, namely, at a paleo-depth of $d_{p}=980 \mathrm{~m}$, where the calculated background $B$ of ${ }^{205} \mathrm{~Pb}$ atoms amounts to about $46 \%$, (see third row of Table 1)

$$
\begin{gathered}
\sigma=4.3 \cdot 10^{-45}\left(2.15 \cdot 10^{-46}\right) \mathrm{cm}^{2}, \\
a=1.26 \cdot 10^{14}\left(1.26 \cdot 10^{12}\right) \mathrm{s}, \\
\lambda=1.48 \cdot 10^{-15}\left(7.4 \cdot 10^{-17}\right) \mathrm{s}^{-1}, \\
\varepsilon=1 \cdot 10^{-3}\left(1 \cdot 10^{-4}\right) .
\end{gathered}
$$

Whereas the geological age $a$ of lorandite and the decay constant $\lambda$ of ${ }^{205} \mathrm{~Pb}$ are by now satisfactorily well known, the solar neutrino capture cross-section $\sigma$ of ${ }^{205} \mathrm{Tl}$ is experimentally unknown. The value assumed in (2.3) is not more than the best educated guess, based on previous estimates of Bahcall and other theorists (Bahcall [12], Wapstra and Audi [13], Braun and Talmi [14], Freedman and Nolte [15], ana Ogawa and Arita [16]). How the nuclear matrix element for the dominant neutrino capture channel into the first excited state of ${ }^{205} \mathrm{~Pb}\left(E^{*}=2.3 \mathrm{keV}\right)$ can be experimentally determined will be outlined in the next Section 2.3. Likewise, the total detection efficiency $\varepsilon$ assumed in (2.3) is only a (optimistic) guess. It is obvious that one of the most demanding problems of LOREX is the measurement of the extremely low concentrations of ${ }^{205} \mathrm{~Pb}$ in potentially available samples of a generally very scarce material. Methods that might be suited to this difficult task are discussed in Section 2.4 . 


\subsection{Determination of the Neutrino Capture Probability into the $2.3 \mathrm{keV}$ State of ${ }^{205} \mathrm{~Pb}$}

From the relative abundance of ${ }^{205} \mathrm{~Pb}$ with respect to ${ }^{205} \mathrm{Tl}$, even corrected for all background effects, one can extract only the time-integrated product of solar neutrino flux and the neutrinocapture probability, leading from the nuclear ground state of ${ }^{205} \mathrm{Tl}\left(I^{\pi}=1 / 2^{+}\right)$to individual excited nuclear states of ${ }^{205} \mathrm{~Pb}^{*}$, according to

$$
{ }^{205} \mathrm{Tl} \text { g.s. }+v_{\mathrm{e}}\left(E_{v e} \geq 52 \mathrm{keV}\right) \longrightarrow{ }^{205} \mathrm{~Pb}^{*}+\mathrm{e}^{-}
$$

with an energy threshold at $E_{v e}=52 \mathrm{keV}$, much lower than the corresponding thresholds of all other radio- or geochemical experiments which are either already performed (e.g., GALLEX) or proposed. The solar pp-neutrinos with a maximum energy of $422 \mathrm{keV}$ can be captured only into the ground state $\left(I^{\pi}=5 / 2^{-}\right)$, the first $\left(E^{*}=2.3 \mathrm{keV}, I^{\pi}=1 / 2^{-}\right)$, and the second excited state $\left(E^{*}=263 \mathrm{keV}, I^{\pi}=3 / 2^{-}\right)$of ${ }^{205} \mathrm{~Pb}$. It is obvious from the wellknown systematic of beta decay that the capture probability into the $2.3 \mathrm{keV}$ state $(\Delta I=0$, parity change) should be by far larger than the capture into the ground state $(\Delta I=2)$ as well as into the second excited state with $\Delta I=1$ (Behrens and Jaenecke [17]). The nuclear matrix element for the transition to the $2.3 \mathrm{keV}$ state in ${ }^{205} \mathrm{~Pb}$ is not known. There is one-and only one-possibility (Kienle [18]) to determine experimentally this unknown nuclear matrix element, namely, by measuring the bound-state beta decay $\left(\beta_{\mathrm{b}}\right.$ decay) of bare (or hydrogenlike) ${ }^{205} \mathrm{Tl}^{81+}$ into hydrogen-like (helium-like) ${ }^{205} \mathrm{~Pb}^{81+}$, according to

$$
{ }^{205} \mathrm{Tl}^{81+} \longrightarrow{ }^{205} \mathrm{~Pb}^{81+*}\left(E^{*}=2.3 \mathrm{keV}\right)+\mathrm{e}_{\mathrm{b}}^{-}+v_{e}(\text { bar }),
$$

where a neutron of the ${ }^{205} \mathrm{Tl}$ atomic nucleus transmutes to a proton, and where a monochromatic electron-antineutrino $\left(v_{\mathrm{e}}(\mathrm{bar})\right)$ is being created together with an electron that remains bound $\left(e_{\mathrm{b}}^{-}\right)$in an inner shell (mainly $\mathrm{K}$ or L-shell) of the daughter ion ${ }^{205} \mathrm{~Pb}^{81+}$. The $Q$ value of this decay amounts to only $52 \mathrm{keV}$. Since the nuclear parts of neutrino capture and of $\beta_{\mathrm{b}}$ decay are identical, a measurement of the bound state beta-decay probability of bare or hydrogen-like ${ }^{205} \mathrm{Tl}$ provides the unknown nuclear matrix element (log $\mathrm{ft}$ value) for the transition to the first excited state of ${ }^{205} \mathrm{~Pb}$ at $E^{*}=2.3 \mathrm{keV}$.

Bound-state beta decay probabilities with comparable small $Q$ values have been measured at the Experimental Storage Ring ESR of GSI in two pioneering experiments, for the examples of bare ${ }^{163} \mathrm{Dy} \rightarrow$ hydrogen-like ${ }^{163} \mathrm{Ho}$ (Jung et al. [20]), and of bare ${ }^{187} \mathrm{Re} \rightarrow$ hydrogen-like ${ }^{187} \mathrm{Os}$ (Bosch et al. [21]), and of bare ${ }^{207} \mathrm{Tl} \rightarrow$ hydrogen-like ${ }^{207} \mathrm{~Pb}$ (Ohtsubo et al. [22]). The well-developed technique of detecting $\beta_{\mathrm{b}}$ decay, as exploited in these experiments, is "Schottky lifetime spectrometry" (Litvinov et al. [23]), where the signals of the stored and electron-cooled parent- and daughter ions, induced on pick-up plates, are steadily recorded, yielding their revolution frequencies which are unambiguously correlated to their corresponding mass-to-charge ratios. From these "Schottky lines," the numbers of both parent and daughter ions are recorded as a function of time, yielding the $\beta_{\mathrm{b}}$ decay probability and, thus, the nuclear matrix element (log $\mathrm{ft}$ value) searched for. However, the revolution frequencies of parent and daughter ions could not be resolved in these experiments due to the very small $Q$ values involved. Therefore, a special technique was applied, namely, the removal of the single bound electron of the daughter ions by means of an internal gas jet acting for a short time. 


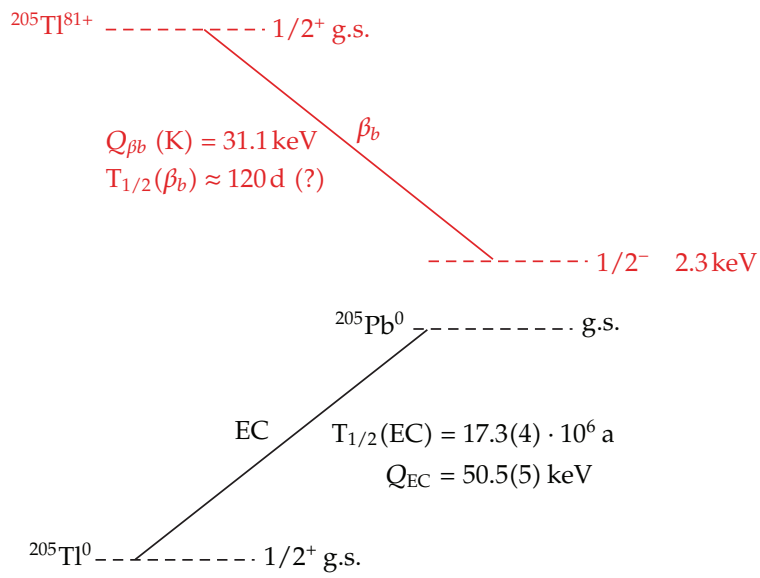

Figure 3: The neutral ${ }^{205} \mathrm{Tl}^{0}$ atom is stable with respect to $\beta^{-}$decay into the continuum since the $Q$ value for this decay is negative, $Q_{\beta-}=-Q_{E C}=-50.5 \mathrm{keV}$. However, for bare $\left({ }^{205} \mathrm{Tl}^{81+}\right)$ or hydrogen-like ${ }^{205} \mathrm{Tl}$ ions bound-state $\beta$ decay becomes allowed, where the created electron remains bound in the K-shell of the daughter ion ${ }^{205} \mathrm{~Pb}^{81+}$. Due to the "saved" K-shell binding energy, the $Q$ value for this decay $\left(Q_{\beta \mathrm{b}}(\mathrm{K})\right)$ gets positive. Both, the capture of solar pp-neutrinos and the bound-state beta decay populate predominantly the first exited state $\left(1 / 2^{-}\right)$of the ${ }^{205} \mathrm{~Pb}$ nucleus at $2.3 \mathrm{keV}$ and share the same nuclear matrix element for this transition. Therefore, the measurement of the bound-state $\beta^{-}$decay probability of bare or hydrogen-like ${ }^{205} \mathrm{Tl}$ ions provides the unknown capture probability of the solar pp-neutrinos by the ${ }^{205} \mathrm{Tl}$ atoms. Based on the $\log \mathrm{ft}$ values of comparable $\beta^{-}$decays, the bound-beta half-life $T_{1 / 2}\left(\beta_{\mathrm{b}}\right)$ of bare ${ }^{205} \mathrm{Tl}$ ions was estimated by Takahashi and Yokoi [19] to about $120 \mathrm{~d}$. Since this extrapolated value has to be regarded as uncertain within (at least) a factor of three, only the measurement of the bound-beta half-life can provide a safe number with a reliable error margin for the capture probability of solar pp-neutrinos by ${ }^{205} \mathrm{Tl}$.

For the corresponding experiment concerning the $\beta_{\mathrm{b}}$ decay of bare ${ }^{205} \mathrm{Tl}$ (see Figure 3 ) with a comparable small $Q$ value, exactly the same detection technique as in the two successful experiments mentioned above has been proposed. However, there were-and still are-serious and too expensive safety restrictions for the use of $\mathrm{Tl}$ in an ion source due to its toxicity, which prevented the realisation of this experiment over the last 18 years. Nonetheless, since this proposal remained all the time on the list of high-priority experiments, we were encouraged to search for another way of its realisation. We proposed as the "new technique" getting bare ${ }^{205} \mathrm{Tl}$ ions their indirect production by in-flight fragmentation of a primary ${ }^{206} \mathrm{~Pb}$ beam in the fragment separator (FRS) together with their subsequent injection into the experimental storage ring (ESR). The decisive point is that at least $10^{6}$ bare ${ }^{205} \mathrm{Tl}$ ions have to be provided and stored, in order to obtain a minimum number of a few $100 \beta_{\mathrm{b}}$ decays within storage times of a couple of hours (the $\beta_{\mathrm{b}}$ half-life of bare ${ }^{205} \mathrm{Tl}$ is estimated to 120 days (Takahashi and Yokoi [19]). By two major achievements of the last years this indispensable number of at least $10^{6}$ stored bare ${ }^{205} \mathrm{Tl}$ ions can now be reached at high confidence (see Figure 4).

(1) By a significant improvement of the output of the lead ion source and the reduction of beam losses, a number of $2 \cdot 10^{9}{ }^{206} \mathrm{~Pb}$ ions could be delivered safely to the FRS already in two experiments. Based on the known cross-section for in-flight fragmentation and the known distribution of atomic charge states, this would yield a number of about $10^{5}$ bare ${ }^{205} \mathrm{Tl}$ ions per injection into the ESR. 


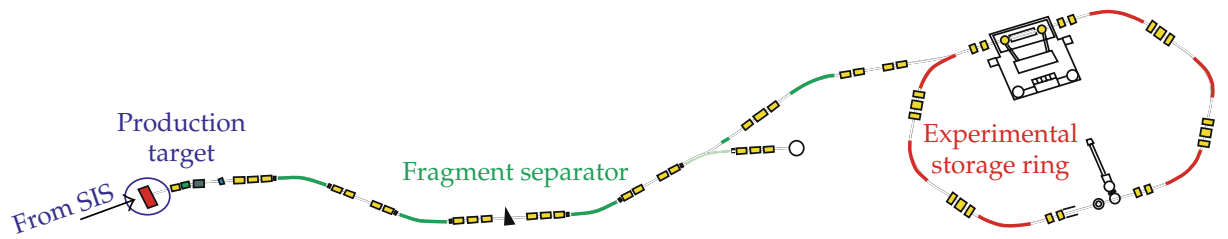

Figure 4: Part of the accelerator facility of GSI, relevant for the proposed measurement of the bound-beta half-life of bare ${ }^{205} \mathrm{Tl}^{81+}$ ions. A beam of ${ }^{206} \mathrm{~Pb}$ ions, accelerated in the synchrotron SIS to an energy of some $100 \mathrm{~A} \mathrm{MeV}$, hits the production target (Be) of the fragment separator FRS, where a plenty of highly-charged ions will be generated by nuclear reactions. With the aid of an appropriate setting of the FRS magnets and by exploiting the $Z$-dependent stopping power in a degrader placed in the symmetry point of the FRS (black triangle), only bare ${ }^{205} \mathrm{Tl}^{81+}$ ions can pass through small slits at the end of the FRS. Those ions will be stored in the experimental storage ring (ESR) and accumulated by repeated injections until a number of at least $10^{6}$ ions will be reached. After the application of electron cooling, the ${ }^{205} \mathrm{Tl}^{81+}$ ions are circulating in the ring for a couple of hours, where a few of them will decay to hydrogen-like ${ }^{205} \mathrm{~Pb}$ by bound-state $\beta$ decay.

(2) By the combination of stochastic cooling and the storage of the injected ions at inner orbits several subsequent injections $(10 \cdots 30)$ can be applied without any losses of the already stored ions ( $\mathrm{rf}$ stacking of fragments). This technique has been successfully applied in several experiments within the last years.

Due to these important steps the reach of $10^{6}$ stored (and cooled) bare ${ }^{205} \mathrm{Tl}$ ions is feasible. Therefore, this new procedure for the determination of the $\beta_{\mathrm{b}}$ decay probability of bare ${ }^{205} \mathrm{Tl}$-and, therewith, of the solar neutrino capture cross-section by ${ }^{205} \mathrm{Tl}$-has been approved in June 2010 by the international experimental board of GSI (ESR-proposal 100). Six days of beam time and the highest priority " $\mathrm{A}$ " were assigned. A copy of this decision is attached in the supplement of this proposal. The experiment is now in the procedure of scheduling. Its realisation within the next 18 months is reliable, taking into account the "waiting list" for high-priority experiments at the FRS-ESR facility.

\subsection{Extraction and Detection of Ultra-Low Amounts of ${ }^{205} \mathrm{~Pb}$ in Lorandite}

One of the key requirements of the geophysical LOREX project is the ultra-sensitive, quantitative detection of the neutrino-induced trace amounts of ${ }^{205} \mathrm{~Pb}$ present in lorandite. For $10 \mathrm{~kg}$ lorandite $\left(\mathrm{TlAsS}_{2}\right)$ one estimates about $3.5-11.6 \times 10^{5}$ atoms of ${ }^{205} \mathrm{~Pb}$ depending on the depth at Allchar at which the respective lorandite sample is mined. This implies a necessary separation factor of about $10^{20}$ between ${ }^{205} \mathrm{~Pb}$ and ${ }^{205} \mathrm{Tl}$ (70\% isotopic abundance). Separation factors of this extreme magnitude are perhaps directly achievable for very shortlived radioisotopes through the measurement of their decay radiation (Low Level Counting, LCC). For ${ }^{205} \mathrm{~Pb}$, with a half-life of about 17 million years and in view of the difficulty to detect electron capture decay, this is impossible.

For the LOREX, therefore, the direct detection and counting of the ${ }^{205} \mathrm{~Pb}$ atoms was proposed, either with mass-spectrometric methods or with measurements of characteristic atomic transition radiation. The intrinsic limitation of these methods to small sample sizes is substantially helped with an initial chemical $\mathrm{Pb}-\mathrm{Tl}$ separation, which has been established to provide a separation factor of $10^{13}$ (Pavićević and Bruechle [24]). For Allchar lorandite the Pb content has been found to be about 1.5 ppm (Pavićević [6]). Thus, after the initial chemical 
$\mathrm{Pb}$ - $\mathrm{Tl}$ separation, a $20 \mathrm{mg} \mathrm{Pb}$ sample with a ${ }^{205} \mathrm{~Pb} / \mathrm{Pb}$-ratio of $\sim 10^{-15}$ will be obtained. The sample will also contain a residual amount of $\sim 10^{12} \mathrm{Tl}$ atoms.

The methods that appear suitable, in principle, for the detection of ${ }^{205} \mathrm{~Pb}$ at trace amount levels under consideration here are low-energy mass spectrometry (specifically ICPMS, i.e., inductively coupled plasma mass spectrometry), high-energy mass spectrometry (i.e., AMS, accelerator mass spectrometry), and laser-induced atomic spectroscopy. The latter includes in particular resonance ionization mass spectrometry (RIMS) and the recently developed atom trap trace analysis (ATTA). Quality criteria in each case are the separation factors for $\mathrm{Pb} / \mathrm{Tl}$ and ${ }^{205} \mathrm{~Pb} / \mathrm{Pb}$ and the overall detection efficiency. The latter is critical for a relevant statistical accuracy of the measured ${ }^{205} \mathrm{~Pb}$ concentration. In summary, the unambiguous detection of the ${ }^{205} \mathrm{~Pb}$ atoms with statistical uncertainty of less than $10 \%$, requires a method that provides fully resolved separation of ${ }^{205} \mathrm{~Pb}$ from ${ }^{205} \mathrm{Tl}$ at the $10^{-7}$ level, and ${ }^{205} \mathrm{~Pb}$ from other lead isotopes at the $10^{-15}$ level, and detection efficiency for ${ }^{205} \mathrm{~Pb}$ atoms of preferably $10^{-2}$ but at a minimum of $10^{-3}$.

High-energy AMS relies on the acceleration of ions to energies where molecules are fully destroyed through breakup in stripper foils, the differential energy loss provides chemical element identification of the remaining ions, and powerful ion-beam detectors could be taken from heavy-ion nuclear physics research. Trace concentrations have been reliably measured for low-mass radioisotopes $(A<40)$ down to values of $10^{-16}$. However, for heavier nuclei the nuclear-charge separation is less pronounced at the typical heavy-ion accelerator because of increased energy-loss straggling and decreasing relative nuclear charge resolution. Earlier experiments of ${ }^{205} \mathrm{~Pb} /{ }^{205} \mathrm{Tl}$ separation at about $6 \mathrm{MeV}$ per nucleon beam energy (Ernst et al. [25]; Henning and Schuell [26]) have produced separation factors of $10^{2}$ to $10^{3}$ between ${ }^{205} \mathrm{~Pb}$ and ${ }^{205} \mathrm{Tl}$, by far not sufficient for the $10^{7}$ factor described above. In addition, the overall efficiency in these studies was found to be less than $10^{-6}$, and in the most optimistic extrapolations it was difficult to see how this could be brought to values better than $10^{-4}$.

A novel variant of AMS was then proposed, based on the recent developments of Schottky mass spectroscopy in a high-energy ion storage ring, following the acceleration of ions to several hundreds of $\mathrm{GeV}$ per nucleon energies and full stripping (Radon et al. [27]). The heavy-ion storage-cooler ring ESR at the GSI Helmholtz Zentrum in Darmstadt, Germany, is uniquely suited for providing a clear-cut solution of the "isobar problem" being such a serious obstacle for tandems. After acceleration in a high-energy synchrotron all atomic species can be fully ionized, and transferred to the ESR where they will be electroncooled, affecting a common sharp velocity for all stored ions. In this case, the revolution frequency in the ESR depends only on the mass-to-charge $(\mathrm{m} / \mathrm{q})$ ratio of the ions which is-for fully stripped atoms-equal to $m / Z$. Therefore, isobars of different nuclear charge $Z$ appear at widely separated revolution frequencies and are easily resolved. One also gets rid of any isobaric molecular contamination, which often represents the most serious obstacle for tandem-based AMS.

Moreover, the ESR provides the ultimate detection limit for heavy $(Z>45)$, highly charged ions: even one single stored and electron-cooled ion can be unambiguously detected (see Figure 5). The high resolving power and ultimate detection sensitivity of the ESR enabled "Schottky mass spectrometry (SMS)" that delivered new and precise atomic masses for more than 180 nuclides (Litvinov et al. [23]). Related studies on other heavy-mass radioisotopes have demonstrated the needed separation factor, but the overall efficiency cannot be brought above $10^{-4}$ for a heavy ion around mass 200 due to ion source efficiencies, the need for multiple stripping, and the general transmission losses experienced in the chain of accelerators to reach the required high energies. A variant we shall consider now is to 


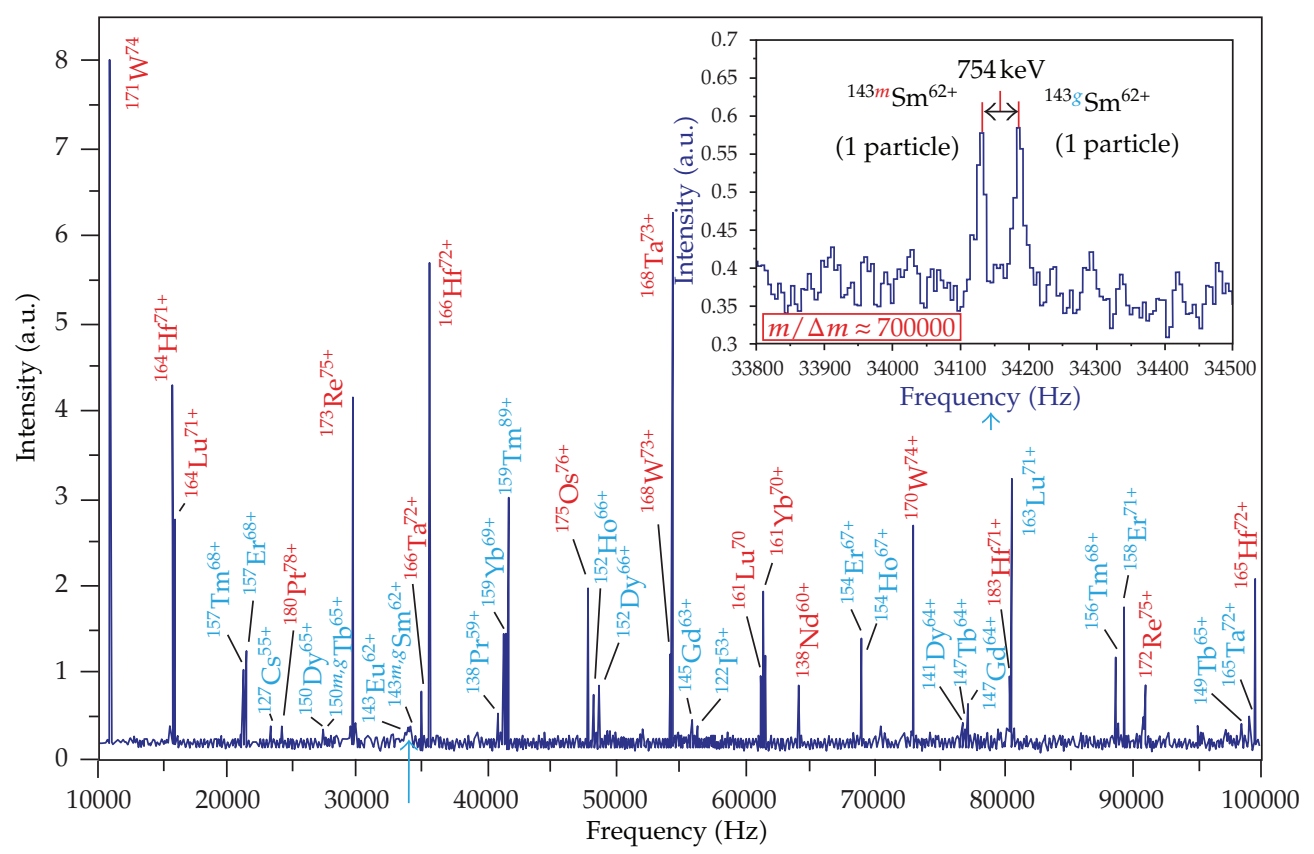

$\Upsilon$ Mass known
$\Upsilon$ Mass unknown

Figure 5: Schottky spectra versus the down-scaled revolution frequencies of stored and cooled nuclei, circulating in the experimental storage ring. Each of the lines shows a different nuclear species. Since for cooled ions a one-to-one correspondence exists between their revolution frequency and their massto-charge ratio, those spectra provide a highly precise mass spectroscopy. The inset shows the Schottky signals of two $\mathrm{Sm}^{62+}$ ions, one of them in the nuclear ground state (at the higher frequency), the other one in a metastable state at an excitation energy of $754 \mathrm{keV}$. This demonstrates convincingly the capability of the ESR to detect-with ultimate sensitivity-one single stored and cooled highly-charged ion together with its accurate mass determination (Figure by courtesy of Litvinov et al. [23]).

inject a lower charge state into the synchrotron accelerator and then to strip at the injection into the storage ring with very high efficiency. This eliminates, in effect, one stripping stage with a resulting broad charge state distribution and thus increases efficiency. Estimated to be around $10^{-4}$ or better, the exact value needs to be experimentally determined. So there has been considerable progress in this "storage ring variant" of AMS, but the overall detection efficiency that can be finally reached finally is still unknown.

Over the past decades, several methods of trace analysis based on laser spectroscopic techniques were proposed and very successfully developed. The high degree of selectivity obtained by these methods is a result of resonant laser-atom interaction. Atoms of different elements interact resonantly with light at significantly different frequencies owing to differences in their atomic structure. Atoms of different isotopes of the same element exhibit isotope shifts, a small change in their resonance frequencies caused by the variation in the nuclear mass and charge radius. By tuning the laser frequencies precisely onto the resonance frequencies of a particular isotope, one can selectively excite, ionize, or manipulate the atoms of this isotope while having a much smaller effect on the other isotopes and elements. 
At the moment the recently developed method of trace analysis with an atom trap appears, with some caveats, a very promising approach. Atom trap trace analysis (ATTA) is a laser-based atom counting method originally developed at Argonne National Laboratory (Chen et al. [28]). Its apparatus consists of lasers and vacuum systems of tabletop size. At its center is a magnetooptical trap, a MOT (Raab et al. [29]). The MOT captures atoms of the desired isotope by using laser beams. When the laser frequency is tuned to within a few natural line widths on the low-frequency side of the resonance of the targeted isotope, only atoms of this particular isotope are trapped. Atoms of other isotopes are either deflected before reaching the trap or allowed to pass through the trap without being captured. The detection method (e.g., a sensitive CCD camera) takes full advantage of the high selectivity of photon burst spectroscopy. A single atom can be trapped and observed for $100 \mathrm{~ms}$ or longer, during which $10^{6}$ fluorescence photons can be induced and as many as $10^{4}$ photons can be detected. These advantages allow single atoms to be counted with a high signal-to-noise ratio, and, since the selectivity depends exponentially on the number of photons detected in a burst, they also ensure a superb selectivity. Indeed ATTA is immune to contamination from other isotopes, elements, or molecules.

For the present proposal we suggest to focus on the Schottky scan developments at the GSI- Darmstadt ESR heavy-ion storage ring. The crucial question that has to be answered in test and pilot experiments is whether or not an overall detection efficiency (including all steps from the ion source to the storage ring) of $10^{-3}$ or better (see the reasoning above) for the ${ }^{205} \mathrm{~Pb}$ ions can be achieved. In parallel we will carefully observe the progress and the developments in ATTA technology with regard to trace analysis of lead isotopes. The sensitivity improvements are key to sample size. The present proposal to obtain the order of $10 \mathrm{~kg}$ lorandite from the Allchahar mine is close to the needed sample size that current trace technologies require. But it is not quite there yet. Any further improvements in the detection techniques, which we believe will occur, have the potential of adding the necessary safety margins. However, this requires serious development and study. Any progress made though might not only benefit the present ${ }^{205} \mathrm{~Pb}$ proposal but radioisotope trace analysis in general.

\section{Summary}

It has been shown that the first two of the four major problems of LOREX, as addressed at the beginning of this work, namely, the age of lorandite and the background-induced amount of ${ }^{205} \mathrm{~Pb}$, have been meanwhile successfully addressed and are near to a final conclusion. In particular, the determination of the erosion rate by cosmogenic nuclides was decisive for getting a first but reliable estimate for paleo-depth and, therefore for the amount of background. Furthermore, it has been demonstrated how the measurement of the boundbeta decay probability of bare ${ }^{205} \mathrm{Tl}$ can provide the unknown neutrino capture probability into the first excited state of ${ }^{205} \mathrm{~Pb}$. The corresponding experiment has been accepted for being performed at the GSI Helmholtzentrum. Finally it has been shown how the small amount of ${ }^{205} \mathrm{~Pb}$ atoms to be expected could be determined by the Schottky noise technique at the ion storage ring of GSI which provides single-ion detection sensitivity. Taking into account the present-day state-of-the-art of all the techniques needed to solve the four problems of LOREX, we conclude that it is realistic to expect the first result for the solar pp neutrino flux averaged over the last 4.2 million years in a foreseeable future. This number will have most probably still a large error margin in the order of $50 \%$ or even more, at the $68 \% \mathrm{CL}$. We expect, however, that this accuracy could be improved with time, and that it might approach a level of $\leq 30 \%$ as discussed by Pavićević et al. [30]. 


\section{Acknowledgment}

The authors thank the FWF - Wien for supporting this project by grant P 20594.

\section{References}

[1] M. S. Freedman, C. M. Stevens, E. P. Horwitz et al., "Solar neutrinos: proposal for a new test," Science, vol. 193, no. 4258, pp. 1117-1119, 1976.

[2] F. Neubauer, M. K. Pavićević, J. Genser, R. Jelenković, B. Boev, and G. Amthauer, " ${ }^{40}$ Ar $/{ }^{39}$ Ar dating of geological events of the Allchar deposit and its host rocks," Geochimica et Cosmochimica Acta, vol. 73, no. 13, supplement 1, article A938, 2009.

[3] Rio Tinto, "Internal report," unpublished, 1999.

[4] S. Janković and R. Jelenković, "Thallium mineralization in the Allchar Sb-As-Tl-Au deposit," Neues Jahrbuch für Mineralogie-Abhandlungen, vol. 167, pp. 283-297, 1994.

[5] M. Troesch and E. Frantz, " ${ }^{40} \mathrm{Ar} /{ }^{39} \mathrm{Ar}$ Alter der Tl-As Mine von Crven Dol, Allchar (Macedonia)," Beiheft zu European Journal of Mineralogy, vol. 4, no. 1, p. 276, 1992.

[6] M. K. Pavićević, "The "Lorex"- Project, Solar neutrino detection with the mineral lorandite (Progress Report)," Neues Jahrbuch für Mineralogie-Abhandlungen, vol. 167, pp. 205-245, 1994.

[7] B. P. Heisinger, D. Lal, A. J. T. Jull et al., "Production of selected cosmogenic radionuclides by muons: 1. Fast muons," Earth and Planetary Science Letters, vol. 200, no. 3-4, pp. 345-355, 2002.

[8] M. K. Pavićević and LOREX Collaboration, "Erosion rate study at the Allchar deposit (Macedonia) based on radioactive and stable cosmogenic nuclides," 2012.

[9] F. J. Hartman, B. Heisinger, G. Korschinek et al., "Proposal for an experiment with fast muons at CERN: determination of cross sections of fast muon induced reactions to cosmogenic radionuclides," CERN/SPSLC 95-8, CERN, Geneva, Switzerland, 1995.

[10] I. V. Aničin, V. Pejović, M. K. Pavićević et al., "On the possibility to simultaneously determine the long-term average fluxes of solar pp-NEUTRINOS and cosmic ray muons," Modern Physics Letters A, vol. 26, no. 17, pp. 1267-1271, 2011.

[11] S. Neumaier, B. Dockorn, E. Nolte, and H. Morinaga, "Signal to background ratio of the geochemical ${ }^{205} \mathrm{Tl}$ solar neutrino experiment," Neues Jahrbuch für Mineralogie-Abhandlungen, vol. 167, pp. 255-263, 1994.

[12] J. N. Bahcall, “Solar neutrino experiments," Reviews of Modern Physics, vol. 50, no. 4, pp. 881-903, 1978.

[13] A. H. Wapstra and G. Audi, "The 1983 atomic mass evaluation: (I). Atomic mass table," Nuclear Physics A, vol. 432, no. 1, pp. 1-54, 1985.

[14] E. Braun and I. Talmi, "On the $\beta$-transition of ${ }^{205} \mathrm{~T} 1$ to ${ }^{205} \mathrm{~Pb}$," in Weak and Electromagnetic Interactions in Nuclei: Proceedings of the International Symposium, H. V. Klapdor, Ed., pp. 47-46, Springer Heidelberg, Berlin, Germany, 1986.

[15] M. S. Freedman and E. E. Nolte, "Revue of the priorities of the ${ }^{205} \mathrm{~Pb}$ experiment," GSI Report 86-9, GSI, Darmstadt, Germany, 1986.

[16] K. Ogawa and K. Arita, "Shell-model study of the first forbidden ${ }^{205} \mathrm{Tl} \rightarrow{ }^{205} \mathrm{~Pb}$ transition and solar neutrino detection," Nuclear Instruments and Methods in Physics Research A, vol. 271, no. 2, pp. 280-285, 1988.

[17] H. Behrens and J. Jaenecke, Numerical Tables for Beta Decay and Electron Capture, 2001.

[18] P. Kienle, "Studies of radioactive decays of completely ionized nuclei in a heavy ion storage ring," Nuclear Instruments and Methods in Physics Research A, vol. 271, no. 2, pp. 277-279, 1988.

[19] K. Takahashi and K. Yokoi, "Beta-decay rates of highly ionized heavy atoms in stellar interiors," Atomic Data and Nuclear Data Tables, vol. 36, pp. 375-409, 1987.

[20] M. Jung, F. Bosch, K. Beckert et al., "First observation of bound-state $\beta^{-}$decay," Physical Review Letters, vol. 69, no. 15, pp. 2164-2167, 1992.

[21] F. Bosch, T. Faestermann, J. Friese et al., "Observation of bound-state $\beta^{-}$decay of fully ionized ${ }^{187}$ Re: ${ }^{187}{ }^{R e}-{ }^{187}$ Os cosmochronometry," Physical Review Letters, vol. 77, no. 26, pp. 5190-5193, 1996.

[22] T. Ohtsubo, F. Bosch, H. Geissel et al., "Simultaneous measurement of $\beta^{-}$decay to bound and continuum electron states," Physical Review Letters, vol. 95, no. 5, Article ID 052501, 4 pages, 2005.

[23] Y. Litvinov, H. Geissel, T. Radon et al., "Mass measurement of cooled neutron-deficient bismuth projectile fragments with time-resolved Schottky mass spectrometry at the FRS-ESR facility," Nuclear Physics A, vol. 756, no. 1-2, pp. 3-38, 2005. 
[24] M. K. Pavićević and W. Bruechle, “Bleiextraktion aus Mineralien Lorandit (TlAsS 2 ), Realgar $\left.\mathrm{As}_{2} \mathrm{~S}_{2}\right)$ und Auripiment $\left(\mathrm{As}_{2} \mathrm{~S}_{3}\right)$," GSI Internal Report, 2005.

[25] H. Ernst, G. Korschinek, P. Kubik et al., " ${ }^{205} \mathrm{~Pb}$ : accelerator mass spectrometry of a very heavy radioisotope and the solar neutrino problem," Nuclear Instruments and Methods in Physics Research B, vol. 5, no. 2, pp. 426-429, 1984.

[26] W. F. Henning and D. Schuell, "On isobar separation and accelerator mass spectrometry of ${ }^{205} \mathrm{~Pb}$," Nuclear Instruments and Methods in Physics Research A, vol. 271, no. 2, pp. 324-327, 1989.

[27] T. Radon, H. Geissel, G. Münzenberg et al., "Schottky mass measurements of stored and cooled neutron-deficient projectile fragments in the element range of $57 \leq \mathrm{Z} \leq 84$," Nuclear Physics $A$, vol. 677, no. 1-4, pp. 75-99, 2000.

[28] C. C. Chen, Y. M. Li, K. Bailey, T. P. O'Connor, L. Young, and Z. T. Lu, “Ultrasensitive isotope trace analyses with a magneto-optical trap," Science, vol. 286, no. 5442, pp. 1139-1141, 1999.

[29] E. L. Raab, M. Prentiss, A. Cable, S. Chu, and D. E. Pritchard, "Trapping of neutral sodium atoms with radiation pressure," Physical Review Letters, vol. 59, no. 23, pp. 2631-2634, 1987.

[30] M. K. Pavićević, F. Bosch, G. Amthauer et al., "New data for the geochemical determination of the solar pp-neutrino flux by means of lorandite mineral," Nuclear Instruments and Methods in Physics Research A, vol. 621, no. 1-3, pp. 278-285, 2010. 

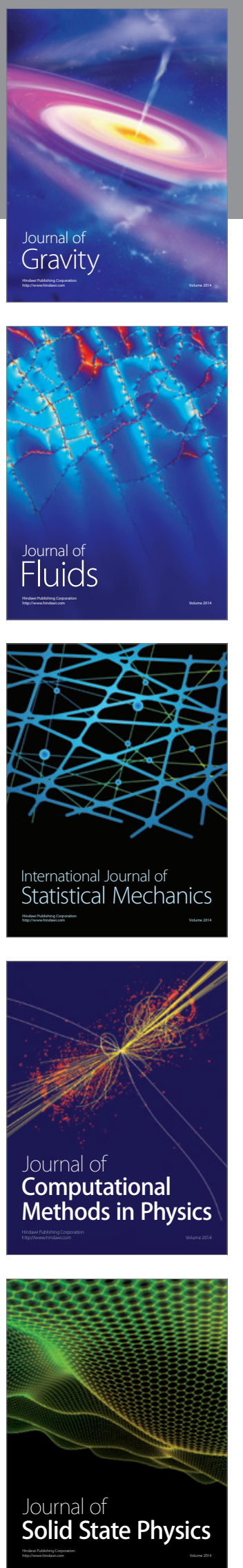

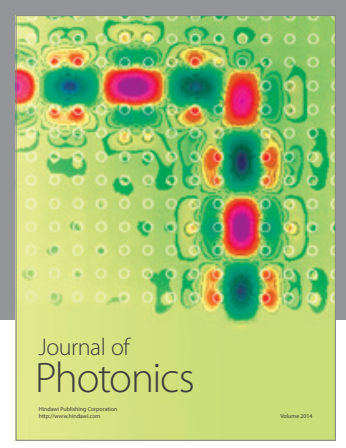

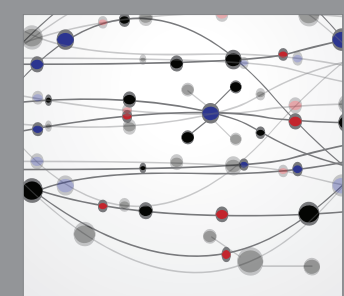

The Scientific World Journal
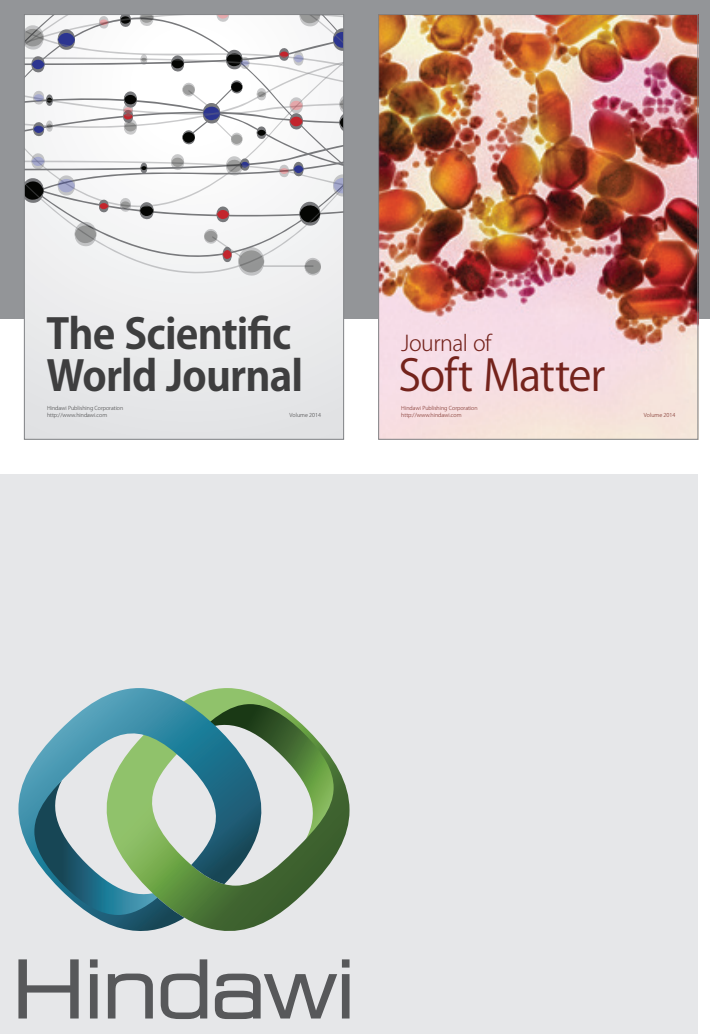

Submit your manuscripts at

http://www.hindawi.com
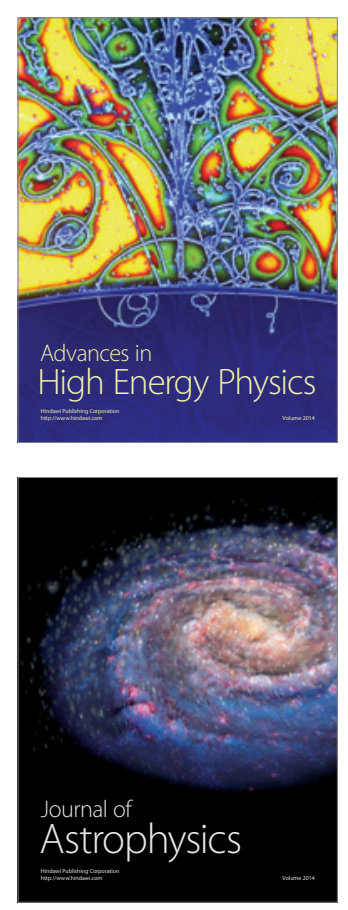
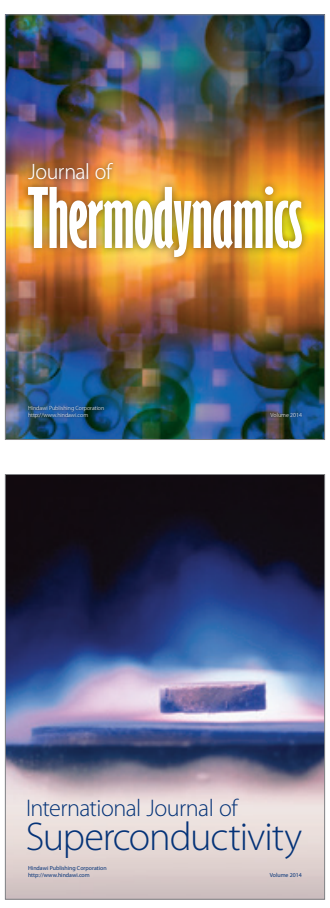
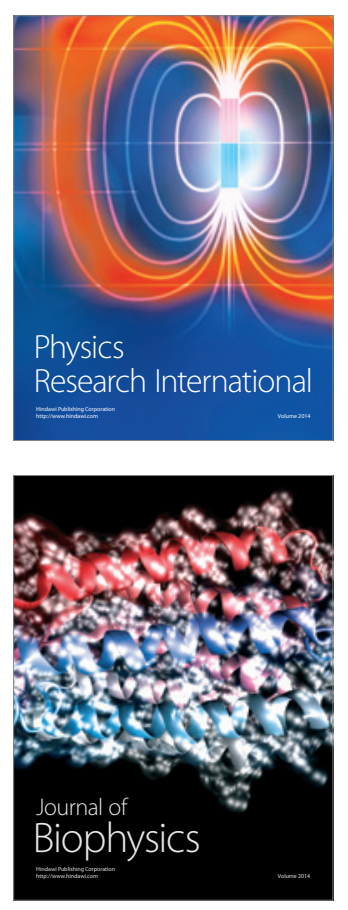
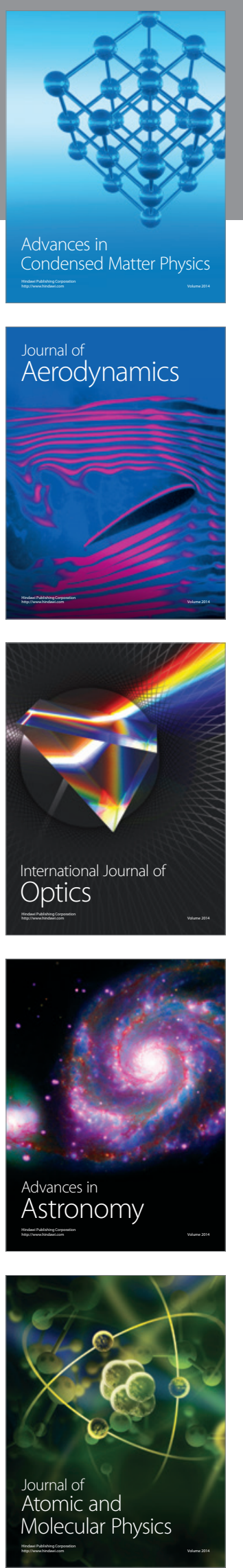